\title{
Sistem Pendukung Keputusan Pemilihan Peserta Jaminan Kesehatan Masyarakat (Jamkesmas) Menerapkan Metode MOORA
}

\author{
Mesran$^{1}$, Swandi Dedi Arnold Pardede ${ }^{2}$, Arahman Harahap ${ }^{2}$, Andysah Putera Utama Siahaan ${ }^{3}$ \\ ${ }^{1}$ STMIK Budi Darma, Medan, Indonesia \\ ${ }^{2}$ Mahasiswa Program Studi Teknik Informatika, STMIK Budi Darma, Medan, Indonesia \\ ${ }^{3}$ Universitas Pembangunan Panca Budi Medan, Medan, Indonesia
}

\begin{abstract}
Abstrak
Sistem pendukung keputusan sebagai sebuah sistem berbasis komputer yang terdiri atas komponen-komponen antara lain komponen sistem bahasa (language), komponen sistem pengetahuan (knowledge) dan komponen sistem pemerosesan masalah (problem processing) yang saling berinteraksi satu dengan yang lainnya, yang membantu pengambilan keputusan melalui pengunaan data dan model-model keputusan untuk memecahkan masalah yang sifatnya semi terstruktur maupun yang tidak terstruktur .Penelitian ini menggunakan Metode MOORA dalam menentukan yang berhak menjadi para peserta Jamkesmas berdasarkan kriteria dengan menggunakan rumus yang hasilnya lebih akurat dan tepat sasaran
\end{abstract}

Kata Kunci: Seleksi Peserta Jamkesmas, Sistem Pendukung Keputusan, MOORA

\section{Abstract}

Decision support system as a computer-based system consisting of components, among other components of the language system (language), components of knowledge systems (knowledge) and components of the problem processing system (problem processing) which interact with each other, which helps decision making through the use of data and decision models to solve problems that are semi-structured and unstructured. This study uses the MOORA Method in determining who is entitled to become participants Jamkesmas based on criteria by using a formula that results more accurate and targeted.

Keywords: Selection of Jamkesmas Participants, Decision Support System, MOORA

\section{PENDAHULUAN}

Kesehatan merupakan sesuatu hal yang sangat penting bagi manusia, yang mana telah diketahui bahwa kesehatan merupakan sesuatu yang sangat berharga dengan dibuktikan begitu banyak jumlah pasien yang dirawat di rumah sakit setiap harinya. Saat ini masih banyak masyarakat yang memilih mempertahankan penyakit yang berada dalam tubuhnya dari pada berobat ke rumah sakit. Hal tersebut dikarenakan berbagai faktor, seperti tidak adanya kemampuan secara ekonomi dikarenakan biaya kesehatan yang mahal.

Jamkesmas merupakan program pemerintah dalam hal pelindungan sosial di bidang kesehatan untuk menjamin masyarakat miskin dan tidak mampu, yang iurannya dibayar oleh pemerintah agar kebutuhan dasar kesehatannya yang layak dapat terpenuhi. Iuran bagi masyarakat miskin dan tidak mampu dalam program Jamkesmas bersumber dari Anggaran Pengeluaran dan Belanja Negara (APBN) dari Mata Anggaran Kegiatan (MAK) belanja bantuan sosial. Pada hakikatnya pelayanan kesehatan terhadap peserta menjadi tanggungjawab dan dilaksanakan bersama oleh Pemerintah Pusat dan Pemerintah Daerah Provinsi/Kabupaten/Kota berkewajiaban memberikan kontribusi sehingga menghasilkan pelayanan yang optimal[1].

Sistem Pendukung Keputusan merupakan sistem berbasis komputer yang mampu menyelesaikan masalah dengan menghasilkan alternatif terbaik untuk mendukung keputusan yang diambil oleh pengambil keputusan[2]. Penerapan sistem informasi ini sudah banyak di gunakan pada perusahaan perusahaan besar yang mendukung fungsi manajemen untuk pengambilan keputusan. Dalam SPK menggunakan metode metode dalam memutuskan yang menjadi alternatif terbaik, seperti WASPAS, TOPSIS, ELECTRE, MOORA[3][4]. Informasi yang dihasilkan merupakan informasi yang efektif yang mendukung kinerja manajemen dalam pengambilan keputusan, terkait tentang masalah yang dihadapi manajer.

Berdasarkan penelitian terdahulu Mesran(2017), bahwa menentukan calon siswa baru yang memiliki nilai terbesar dan dapat diterima dalam calon siswa unggul dengan menggunakan metode MOORA,alternatif A1 adalah calon siswa baru yang memiliki nilai terbesar dan dapat diterima[5]. Kemudian penelitian yang diteliti oleh Muhammad Ashari dan Fitri Mintarsih pada tahun 2017, bahwa pemilihan bibit ikan tawar dengan menggunakan metode MOORA, ikan lele sebagai alternatif terbaik bibit ikan air tawar dengan nilai -0,1009.

Sesuai Keputusan Menteri Kesehatan Republik Indonesia Nomor 125/Menkes/SK/II/2008 program JAMKESMAS bertujuan untuk meningkatkan akses dan mutu pelayanan kesehatan terhadap seluruh masyarakat miskin dan tidak mampu agar tercapai derajat kesehatan masyarakat yang optimal secara efektif dan efisien. Penyelenggara pelayanan kesehatan yang semakin kompleks menuntut penanganan professional yang mampu mengatasi suatu masalah dalam penerima jamkesmas bagi masyarakat agar program Jamkesmas tepat sasaran. 


\section{TEORITIS}

\subsection{Metode Multi-Objective Optimization on The Basic of Ratio Analysis (MOORA)}

Metode Moora menggunakan perkalian sebagai untuk menghubungkan rating atribut,dimana rating atribut harus dipangkatkan dulu dengan bobot yang bersangkutan, Preferensi untuk alternatif Si.

Secara umum, prosedur MOORA[6] meliputi langkah-langkah sebagai berikut:

1. Penentuan nilai matrik

Menentukan Tujuan untuk mengindentifikasi atribut evaluasi yang bersangkutan

2. Normalisasi matriks

Mewakilkan semua informasi yang tersedia untuk setiap atrribut dalam bentuk matriks keputusan.

$$
\mathrm{X}=\left[\begin{array}{lll}
x_{11} & x_{12} & x_{1 n} \\
x_{21} & x_{22} & x_{2 n} \\
x_{31} & x_{32} & x_{3 n}
\end{array}\right]
$$

3. Normalisasi matriks

Breaures (2008) menyimpulkan bahwa untuk penyebut, pilihan terbaik adalah akar kuadrat dari jumlah kuadrat dan setiap alternatif peratribut.

$$
\begin{aligned}
& \mathrm{X}^{*}{ }_{\mathrm{ij}=\mathrm{Xij}} / \sqrt{\left[\sum_{i=1}^{m} x_{i j}^{2}\right]} \\
& \text { Untuk } \mathrm{j}=12 \ldots \mathrm{m}
\end{aligned}
$$

4. Mengoptimalkan Atribut

Untuk optimasi Multiobjektif, ukuran yang dinormalisasi ditambahkan dalam kasus maksimasi (untuk atribut yang menguntungkan) dan dikurangi dalam kasus minimasi (untuk atribut yang tidak menguntungkan).

$$
\mathrm{Y}_{\mathrm{i}=} \sum_{j=1}^{g}-\sum_{j=g+1}^{n} x_{i j}^{x}
$$

Dimana $G$ adalah jumlah atribut yang akan dimaksimalkan, (n-g) adalah jumlah atribut yang akan diminimalkan, dan yi adalah nilai penilaian yang telah dinormalisasikan dari altenatif 1 terhadap semua atribut. Saat atribut bobot dioertimbangkan, persamaan 3 menjadi sebagai berikut:

$$
\mathrm{Yi}=\sum_{j=1}^{g} W_{\mathrm{j}} \mathrm{X}_{\mathrm{Ij}}^{*}-\sum_{j=g+1}^{n} W_{\mathrm{j}} W_{i j}^{*}
$$

$\mathrm{Wj}$ adalah bobot dari $\mathrm{J}^{\text {th }}$ atribut, yang dapat ditentukan dengan menerapkan applying analtic hieararchy process (AHP) atau metode entrophy.

5. Perangkingan nilai $Y$

Nilai Yi bisa positif atau negatif tergantung dari total maksimak dan minimal dalam matriks keputusan. Sebuah urutan peringkat dan Yi menujukan pilihan terakhir.

Alternatif terbaik memiliki nilai Yi tertinggi, sedangkan alternatif terburuk memiliki nilai yang rendah.

\section{ANALISA DAN PEMBAHASAN}

Pimpinan puskesmas terkadang sering mengalami kesulitan dalam mendapatkan keputusan untuk menghitung dan menentukan suatu keputusan yang dihasilkan. Berdasarkan permasalahan diatas maka dibentuk sebuah sistem pengkajian untuk memecahkan masalah yang dialami oleh Puskesmas agar tidak terjadi kekeliruan.

Proses proses yang dilakukan pada Multi-Objective Optimization On The Basic Of Ratio Analysist (MOORA) memerlukan kriteria-kriteria yang mempegaruhi peserta (alternatif) dalam perhitungan.Kriteria (C) dapat dilihat pada tabel berikut.

Tabel 1. Kriteria

\begin{tabular}{|l|l|c|c|}
\hline Kriteria & Keterangan & Bobot & Jenis \\
\hline $\mathrm{C}_{1}$ & Pendapatan & 0.25 & Cost \\
\hline
\end{tabular}
Mesran | http://ejurnal.stmik-budidarma.ac.id/index.php/mib | Page | 17




\begin{tabular}{|l|l|c|c|}
\hline Kriteria & \multicolumn{1}{|c|}{ Keterangan } & Bobot & Jenis \\
\hline $\mathrm{C}_{2}$ & Lamanya Warga Tinggal & 0.20 & Benefit \\
\hline $\mathrm{C}_{3}$ & Perkerjaan & 0.20 & Cost \\
\hline $\mathrm{C}_{4}$ & Jenis Dinding Rumah & 0.20 & Cost \\
\hline $\mathrm{C}_{5}$ & Jenis Lantai Rumah & 0.15 & Cost \\
\hline
\end{tabular}

Tabel 2 merupakan tabel yang berisikan pembobotan untuk perkerjaan warga

Tabel 2. Menentukan kriteria Perkerjaan warga

\begin{tabular}{|c|c|c|}
\hline Range & Nilai & Bobot \\
\hline Tukang becak & Buruk & 0.25 \\
\hline Petani & Kurang & 0.5 \\
\hline Wiraswasta & Cukup & 0.75 \\
\hline Karyawan & baik & 1 \\
\hline
\end{tabular}

Tabel 3 merupakan tabel yang berisikan Pembobotan untuk jenis lantai rumah.

Tabel 3. Menentukan Kriteria untuk jenis lantai rumah

\begin{tabular}{|c|c|c|}
\hline Range & Nilai & Bobot \\
\hline Lantai Rumah masih tanah & Buruk & 0.5 \\
\hline Lantai Rumah semen & Kurang & 0.25 \\
\hline Lantai rumah keramik & cukup & 0.75 \\
\hline
\end{tabular}

Tabel 4 merupakan tabel yang berisikan Pembobotan untuk jenis Dinding Rumah

Tabel 4. Menentukan Kriteria Jenis Dingding rumah

\begin{tabular}{|c|c|c|}
\hline Range & Nilai & Bobot \\
\hline Fisik Dinding Rumah terbuat dari tepas & Buruk & 0.25 \\
\hline Dingding bangunan terbuat dari papan & Kurang & 0.5 \\
\hline Dingding bangunan permanen/tembok batu & Cukup & 0.75 \\
\hline Dingding bangunan tergolong mewah luas & Baik & 1 \\
\hline
\end{tabular}

Tabel 5 merupakan tabel yang berisikan data masyarakat yang terdapat di daerah Galang. Data tersebut merupakan data masyarakat yang ingin mendapatkan Jamkesmas.

Tabel 5. Data Calon peserta Jamkesmas

\begin{tabular}{|l|r|c|l|c|c|}
\hline Alternatif & $\mathrm{C}_{1}$ & $\mathrm{C}_{2}$ & $\mathrm{C}_{3}$ & $\mathrm{C}_{4}$ & $\mathrm{C}_{5}$ \\
\hline Adelan $\left(\mathrm{A}_{1}\right)$ & 500.000 & 15 & Tukang Becak & Papan & Semen \\
\hline Suwito & 600.000 & 6 & Petani & Papan & Semen \\
\hline Manisem & 1.000 .000 & 3 & Wiraswasta & Papan & Tanah \\
\hline Kardik & 650.000 & 10 & Petani & Papan & Semen \\
\hline Mislam & 500.000 & 7 & Tukang Becak & Papan & Semen \\
\hline Sukirah & 600.000 & 3 & Petani & Tepas & Tanah \\
\hline Nuriadi & 400.000 & 5 & Tukang Becak & Tepas & Tanah \\
\hline Sutiyem & 700.000 & 10 & Petani & Papan & Semen \\
\hline Poniman & 500.000 & 8 & Tukang Becak & Papan & Semen \\
\hline Sugiatik & 1.200 .000 & 10 & Wiraswasta & Papan & Semen \\
\hline
\end{tabular}

Berdasarkan pembobotan pada tabel 2-4, maka alternatif yang terdapat pada tabel 4 dapat dilihat pada tabel berikut ini. 


$$
\left[\begin{array}{llll}
0,6467(0,4) & 0,2847(0,25) & 0,4146(0,2) & 0,4092(0,15) \\
0,3104(0,4) & 0,4746(0,25) & 0,4738(0,2) & 0,4385(0,15) \\
0,2587(0,4) & 0,5923(0,25) & 0,5923(0,2) & 0.5262(0,15) \\
0,5174(0,4) & 0,3796(0,25) & 0,3554(0,2) & 0,3800(0,15) \\
0,3880(0,4) & 0,4746(0,25) & 0,3554(0,2) & 0,4677(0,15)
\end{array}\right] x W j
$$

Hasil perkaliian dari penyetaraan bobot

Tabel 5. Data Rating Kecocokan Bobot dan Kriteria

\begin{tabular}{|c|r|c|c|c|c|}
\hline Alternatif & $\mathrm{C}_{1}$ & $\mathrm{C}_{2}$ & $\mathrm{C}_{3}$ & $\mathrm{C}_{4}$ & $\mathrm{C}_{5}$ \\
\hline $\mathrm{A}_{1}$ & 500.000 & 15 & 0,25 & 0.5 & 0.25 \\
\hline $\mathrm{A}_{2}$ & 600.000 & 6 & 0.5 & 0.5 & 0.25 \\
\hline $\mathrm{A}_{3}$ & 1.000 .000 & 3 & 0.75 & 0.5 & 0.5 \\
\hline $\mathrm{A}_{4}$ & 650.000 & 10 & 0.5 & 0.5 & 0.25 \\
\hline $\mathrm{A}_{5}$ & 500.000 & 7 & 0,25 & 0.5 & 0.25 \\
\hline $\mathrm{A}_{6}$ & 600.000 & 3 & 0.5 & 0.25 & 0.5 \\
\hline $\mathrm{A}_{7}$ & 400.000 & 5 & 0,25 & 0.25 & 0.5 \\
\hline $\mathrm{A}_{8}$ & 700.000 & 10 & 0.5 & 0.5 & 0.25 \\
\hline $\mathrm{A}_{9}$ & 500.000 & 8 & 0,25 & 0.5 & 0.25 \\
\hline $\mathrm{A}_{10}$ & 1.200 .000 & 10 & 0.75 & 0.5 & 0.25 \\
\hline
\end{tabular}

Setelah didapatkan nilai nilai alternatif yang telah di bobotkan, maka dilakukan pemrosesan keputusan menggunakan metode MOORA.

1. Mempersiapkan matrik keputusan $X$

$x=\left|\begin{array}{ccccc}500.000 & 15 & 0,25 & 0.5 & 0.25 \\ 600.000 & 6 & 0.5 & 0.5 & 0.25 \\ 1.000 .000 & 3 & 0.75 & 0.5 & 0.5 \\ 650000 & 10 & 0.5 & 0.5 & 0.25 \\ 500000 & 7 & 0.25 & 0.5 & 0.25 \\ 600000 & 3 & 0.5 & 0.25 & 0.5 \\ 400000 & 5 & 0.25 & 0.25 & 0.5 \\ 700000 & 10 & 0.5 & 0.5 & 0.25 \\ 500000 & 8 & 0.25 & 0.5 & 0.25 \\ 1200000 & 10 & 0.75 & 0.5 & 0.25\end{array}\right|$

2. Melakukan normalisasi matrik X

$$
\begin{aligned}
C_{1} & =\sqrt{500000^{2}+600000^{2}+1000000^{2}+650000^{2}+500000^{2}+600000^{2}+400000^{2}+700000^{2}+} \\
& =\sqrt{4982500000000}=22.321 \quad 500000^{2}+1200000^{2}
\end{aligned}
$$

$\mathrm{A}_{11}=500.000 / 22.321=0.2240$

$\mathrm{A}_{12}=600.000 / 22.321=0.2688$

$\mathrm{A}_{13}=1.000 .000 / 22.321=0.4480$

$\mathrm{A}_{14}=650.000 / 22.321=0.2912$

$\mathrm{A}_{15}=500.000 / 22.321=0.2240$

$\mathrm{A}_{16}=600.000 / 22.321=0.2688$

$\mathrm{A}_{17}=400.000 / 22.321=0.1792$

$\mathrm{A}_{18}=700.000 / 22.321=0.3136$

$\mathrm{A}_{19}=500.000 / 22.321=0.2240$

$\mathrm{A}_{110}=1200.000 / 22.321=0.5376$ 


$$
\begin{aligned}
C_{2} & =\sqrt{15^{2}+6^{2}+3^{2}+10^{2}+7^{2}+3^{2}+5^{2}+10^{2}+8^{2}+10^{2}} \\
& =\sqrt{692}=26.305
\end{aligned}
$$

$\mathrm{A}_{12}=15 / 26.305=0.5702$

$\mathrm{A}_{22}=6 / 26.305=0.2280$

$\mathrm{A}_{32}=3 / 26.305=0.1140$

$\mathrm{A}_{42}=10 / 26.305=0.3801$

$\mathrm{A}_{52}=7 / 26.305=0.26610$

$\mathrm{A}_{62}=3 / 26.305=0.1140$

$\mathrm{A}_{72}=5 / 26.305=0.1900$

$\mathrm{A}_{82}=10 / 26.305=0.3801$

$\mathrm{A}_{92}=8 / 26.305=0.3041$

$\mathrm{A}_{102}=10 / 26.305=0.3801$

$$
\begin{aligned}
C_{3} & =\sqrt{0.25^{2}+0.5^{2}+0.75^{2}+0.5^{2}+0.25^{2}+0.5^{2}+0.25^{2}+0.5^{2}+0.25^{2}+0.75^{2}} \\
& =\sqrt{2.375}=1.541
\end{aligned}
$$

$\mathrm{A}_{13}=0.25 / 1.541=0.1622$

$\mathrm{A}_{23}=0.5 / 1.541=0.3244$

$\mathrm{A}_{33}=0.75 / 1.541=0.4866$

$\mathrm{A}_{43}=0.5 / 1.541=0.3244$

$\mathrm{A}_{53}=0.25 / 1.541=0.1622$

$\mathrm{A}_{63}=0.5 / 1.541=0.3244$

$\mathrm{A}_{73}=0.25 / 1.541=0.1622$

$\mathrm{A}_{83}=0.5 / 1.541=0.3244$

$\mathrm{A}_{93}=0.25 / 1.541=0.1622$

$\mathrm{A}_{103}=0.75 / 1.541=0.4866$

$$
\begin{aligned}
C_{4} & =\sqrt{0.5^{2}+0.5^{2}+0.5^{2}+0.5^{2}+0.5^{2}+0.25^{2}+0.25^{2}+0.5^{2}+0.5^{2}+0.5^{2}} \\
& =\sqrt{2.125}=1.4577
\end{aligned}
$$

$\mathrm{A}_{14}=0.5 / 1.4577=0.3430$

$\mathrm{A}_{24}=0.5 / 1.4577=0.3430$

$\mathrm{A}_{34}=0.5 / 1.4577=0.3430$

$\mathrm{A}_{44}=0.5 / 1.4577=0.3430$

$\mathrm{A}_{54}=0.5 / 1.4577=0.3430$

$\mathrm{A}_{64}=0.25 / 1.4577=0.1715$

$\mathrm{A}_{74}=0.25 / 1.4577=0.1715$

$\mathrm{A}_{84}=0.5 / 1.4577=0.3430$

$\mathrm{A}_{94}=0.5 / 1.4577=0.3430$

$\mathrm{A}_{104}=0.5 / 1.4577=0.3430$

$$
\begin{aligned}
C_{5} & =\sqrt{0.25^{2}+0.25^{2}+0.5^{2}+0.25^{2}+0.25^{2}+0.5^{2}+0.5^{2}+0.25^{2}+0.25^{2}+0.25^{2}} \\
& =\sqrt{1.25}=1.180
\end{aligned}
$$

$\mathrm{A}_{15}=0.25 / 1.180=0.2118$

$\mathrm{A}_{25}=0.25 / 1.180=0.2118$

$\mathrm{A}_{35}=0.5 / 1.180=0.4237$

$\mathrm{A}_{45}=0.25 / 1.180=0.2118$

$\mathrm{A}_{55}=0.25 / 1.180=0.2118$

$\mathrm{A}_{65}=0.5 / 1.180=0.4237$ 
MEDIA INFORMATIKA BUDIDARMA, Vol 2, No 2, April 2018

ISSN 2614-5278 (media cetak)

ISSN 2548-8368 (media online)

Hal 16-22

$\mathrm{A}_{75}=0.5 / 1.180=0.4237$

$\mathrm{A}_{85}=0.25 / 1.180=0.2118$

$\mathrm{A}_{95}=0.25 / 1.180=0.2118$

$\mathrm{A}_{105}=0.25 / 1.180=0.2118$

Hasilnya dari Nirmalisasi Matriks X diperoleh matriks $X_{i j}^{*}$ dilihat berikut ini.

$\mathrm{X}_{\mathrm{ij}}^{*}=\left|\begin{array}{ccccc}0.2240 & 0.5702 & 0.1622 & 0.3430 & 0.2118 \\ 0.2688 & 0.2280 & 0.3244 & 0.3430 & 0.2118 \\ 0.4480 & 0.1140 & 0.4866 & 0.3430 & 0.4237 \\ 0.2912 & 0.3801 & 0.3244 & 0.3430 & 0.2118 \\ 0.2240 & 0.2661 & 0.1622 & 0.3430 & 0.2118 \\ 0.2688 & 0.1140 & 0.3244 & 0.1715 & 0.4237 \\ 0.1792 & 0.1900 & 0.1622 & 0.1715 & 0.4237 \\ 0.3136 & 0.3801 & 0.3244 & 0.3430 & 0.2118 \\ 0.2240 & 0.3041 & 0.622 & 0.3430 & 0.2118 \\ 0.5376 & 0.3801 & 0.4866 & 0.3430 & 0.2118\end{array}\right|$

3. Mengoptimalkan atribut Menyertakan bobot dalam pencarian yang ternormalisasi

,$X_{w j}=\left|\begin{array}{lllll}0.2240(0.25) & 0.5702(0.20) & 0.1622(0.20) & 0.3430(0.20) & 0.2118(0.15) \\ 0.2688(0.25) & 0.2280(0.20) & 0.3244(0.20) & 0.3430(0.20) & 0.2118(0.15) \\ 0.4480(0.25) & 0.1140(0.20) & 0.4866(0.20) & 0.3430(0.20) & 0.4237(0.15) \\ 0.2912(0.25) & 0.3801(0.20) & 0.3244(0.20) & 0.3430(0.20) & 0.2118(0.15) \\ 0.2240(0.25) & 0.2661(0.20) & 0.1622(0.20) & 0.3430(0.20) & 0.2118(0.15) \\ 0.2688(0.25) & 0.1140(0.20) & 0.3244(0.20) & 0.1715(0.20) & 0.4237(0.15) \\ 0.1792(0.25) & 0.1900(0.20) & 0.1622(0.20) & 0.1715(0.20) & 0.4237(0.15) \\ 0.3136(0.25) & 0.3801(0.20) & 0.3244(0.20) & 0.3430(0.20) & 0.2118(0.15) \\ 0.2240(0.25) & 0.3041(0.20) & 0.6220(0.20) & 0.3430(0.20) & 0.2118(0.15) \\ 0.5376(0.25) & 0.3801(0.20) & 0.4866(0.20) & 0.3430(0.20) & 0.2118(0.15)\end{array}\right|$

Hasil perkalian dengan bobot kriteria, yaitu:

$x=\left|\begin{array}{lllll}0.0560 & 0.1140 & 0,0324 & 0.0686 & 0.0317 \\ 0.0672 & 0.0456 & 0.0648 & 0.0686 & 0.0317 \\ 0.1120 & 0.0228 & 0.0973 & 0.0686 & 0.0635 \\ 0.0728 & 0.0760 & 0.0648 & 0.0686 & 0.0317 \\ 0.0560 & 0.0532 & 0.0324 & 0.0686 & 0.0317 \\ 0.0672 & 0.2280 & 0.0648 & 0.0343 & 0.0635 \\ 0.0448 & 0.0380 & 0.0324 & 0.0343 & 0.0635 \\ 0.0784 & 0.0760 & 0.0648 & 0.0686 & 0.0317 \\ 0.0560 & 0.0608 & 0.1244 & 0.0686 & 0.0317 \\ 0.0140 & 0.0760 & 0.0973 & 0.0686 & 0.0317\end{array}\right|$

Tabel 6. Daftar Yi

\begin{tabular}{|c|c|c|c|}
\hline Alternatif & Maximun $\left(\mathrm{C}_{1}+\mathrm{C}_{2}+\mathrm{C}_{3}\right)$ & Minimun $\left(\mathrm{C}_{4}+\mathrm{C}_{5}\right)$ & $\mathrm{Yi}=$ Max - Min \\
\hline $\mathrm{A}_{1}$ & 0.2024 & 0.1003 & 0.1021 \\
\hline $\mathrm{A}_{2}$ & 0.1776 & 0.1003 & 0.0773 \\
\hline $\mathrm{A}_{3}$ & 0.2321 & 0.1321 & 0.1000 \\
\hline $\mathrm{A}_{4}$ & 0.2136 & 0.1003 & 0.1133 \\
\hline $\mathrm{A}_{5}$ & 0.1416 & 0.1003 & 0.0413 \\
\hline $\mathrm{A}_{6}$ & 0.3600 & 0.0978 & 0.2622 \\
\hline $\mathrm{A}_{7}$ & 0.1152 & 0.0978 & 0.0174 \\
\hline $\mathrm{A}_{8}$ & 0.2192 & 0.1003 & 0.1189 \\
\hline $\mathrm{A}_{9}$ & 0.2412 & 0.1003 & 0.1409 \\
\hline $\mathrm{A}_{10}$ & 0.1873 & 0.1003 & 0.0870 \\
\hline
\end{tabular}

Mesran | http://ejurnal.stmik-budidarma.ac.id/index.php/mib | Page | 21 
Dari hasil diatas, dapat dilihat rangking setiap alternatif dari peserta Jamkesmas pada tabel berikut:

Table 7. Hasil rangking

\begin{tabular}{|c|c|c|}
\hline Alternatif & Hasil & Rangking \\
\hline $\mathrm{A}_{6}$ & 0.2622 & 1 \\
\hline $\mathrm{A}_{9}$ & 0.1409 & 2 \\
\hline $\mathrm{A}_{8}$ & 0.1189 & 3 \\
\hline $\mathrm{A}_{4}$ & 0.1133 & 4 \\
\hline $\mathrm{A}_{1}$ & 0.1021 & 5 \\
\hline $\mathrm{A}_{3}$ & 0.1000 & 6 \\
\hline $\mathrm{A}_{10}$ & 0.0870 & 7 \\
\hline $\mathrm{A}_{2}$ & 0.0773 & 8 \\
\hline $\mathrm{A}_{5}$ & 0.0413 & 9 \\
\hline $\mathrm{A}_{7}$ & 0.0174 & 10 \\
\hline
\end{tabular}

Alternatif $\mathrm{A}_{6}>\mathrm{A}_{9}>\mathrm{A}_{8}$ maka alternatif $\mathrm{A}_{6}$ merupakan alternatif yang terbaik dibanding alternatif yang lainnya.

\section{KESIMPULAN}

Berdasarkan pembahasan diatas, peneliti menarik kesimpulan, sebagai berikut:

1. Penentuan kriteria - kriteria dalam pemilihan peserta jamkesmas sangat mempegaruhi hasil perhitungan MOORA.

2. Penerapan metode MOORA cukup mudah digunakan sebagai cara untuk pemilihan peserta Jamkesmas karena langkah - langkah penyelesaiannya cukup sederhana.

3. Sistem pendukung keputusan dapat mengatasi permasalahan pemilihan peserta Jamkesmas menjadi lebih tersistem dan tepat pada masyarakat yang benar-benar membutuhkan

\section{REFERENCES}

[1] M. Sholihin, N. Fuad, and N. Khamiliyah, "Sistem Pendukung Keputusan Penentuan Warga Penerima Jamkesmas Dengan Metode Fuzzy Tsukamoto,” J. Tek., vol. 5, no. 2 SPK, pp. 501-506, 2013.

[2] Kusrini, Sistem Pendukung Keputusan dan Aplikasinya. Yogyakarta: Andi, 2007.

[3] S. Syamsudin and R. Rahim, "Study Approach Technique for Order of Preference by Similarity to Ideal Solution (TOPSIS)," Int. J. Recent Trends Eng. Res., vol. 3, no. 3, pp. 268-285, 2017.

[4] Mesran, K. Tampubolon, R. D. Sianturi, F. T. Waruwu, and A. P. U. Siahaan, "Determination of Education Scholarship Recipients Using Preference Selection Index," Int. J. Sci. Res. Sci. Technol., vol. 3, no. 6, pp. 230-234, 2017.

[5] Mesran, R. K. Hondro, M. Syahrizal, A. P. U. Siahaan, R. Rahim, and Suginam, "Student Admission Assessment using Multi-Objective Optimization on the Basis of Ratio Analysis (MOORA)," J. Online Jar. COT POLIPT, vol. 10, no. 7, pp. 1-6, 2017.

[6] N. W. Al-Hafiz, Mesran, and Suginam, "Sistem Pendukung Keputusan Penentukan Kredit Pemilikan Rumah Menerapkan MultiObjective Optimization on the Basis of Ratio Analysis ( Moora )," KOMIK (Konferensi Nas. Teknol. Inf. dan Komputer), vol. I, no. 1 , pp. 306-309, 2017.

[7] Fadlina, L. T. Sianturi, A. Karim, Mesran, and A. P. U. Siahaan, "Best Student Selection Using Extended Promethee II Method," Int. J. Recent Trends Eng. Res., vol. 3, no. 8, pp. 21-29, 2017.

[8] S. Dian Utami Sutiksno, P. Rufaidah, H. Ali, and W. Souisa, "A Literature Review of Strategic Marketing and The Resource Based View of The Firm," Int. J. Econ. Res., vol. 14, no. 8, pp. 59-73, 2017.

[9] S. Kusumadewi, S. Hartati, A. Harjoko, and R. Wardoyo, Fuzzy Multi-Attribute Decision Making (Fuzzy MADM). Yogyakarta: Graha Ilmu, 2006.

[10] T. Murti, L. A. Abdillah, and M. Sobri, "Sistem Penunjang Keputusan Kelayakan Pemberian Pinjaman Dengan Metode Fuzzy Tsukamoto," Semin. Nas. Inov. dan Tren (SNIT)2015, pp. 252-256, 2015.

[11] G. Ginting, Fadlina, Mesran, A. P. U. Siahaan, and R. Rahim, "Technical Approach of TOPSIS in Decision Making," Int. J. Recent Trends Eng. Res., vol. 3, no. 8, pp. 58-64, 2017.

[12] J. Simarmata, Pengenalan Teknologi Komputer dan Informasi. Yogyakarta: Andi, 2006.

[13] M. I. Setiawan et al., "Business Centre Development Model of Airport Area in Supporting Airport Sustainability in Indonesia," J. Phys. Conf. Ser., vol. 954, no. 1, p. 12024, 2018.

[14] D. Handoko, M. Mesran, S. D. Nasution, Y. Yuhandri, and H. Nurdiyanto, "Application Of Weight Sum Model (WSM) In Determining Special Allocation Funds Recipients," IJICS (International J. Informatics Comput. Sci., vol. 1, no. 2, pp. 31-35, 2017.

[15] H. Nurdiyanto and Heryanita Meilia, "SISTEM PENDUKUNG KEPUTUSAN PENENTUAN PRIORITAS PENGEMBANGAN INDUSTRI KECIL DAN MENENGAH DI LAMPUNG TENGAH MENGGUNAKAN ANALITICAL HIERARCHY PROCESS (AHP)," in Seminar Nasional Teknologi Informasi dan Multimedia 2016, 2016, no. February, pp. 1-7.

[16] Jimmy Abdel Kadar, D Agustono, and Darmawan Napitupulu, "Optimization of Candidate Selection Using Naive Bayes : Case Study in Company X Optimization of Candidate Selection Using Naive Bayes : Case Study in Company X," J. Phys. Conf. Ser., vol. 12, no. $1,2016$. 